\title{
Anatomic Image-Based Classification of Lumbar Intervertebral Disc Pathologies
}

\author{
Said G. Osman ${ }^{1}$ \\ 1. Surgery, Frederick Memorial Hospital, Frederick, Maryland, USA \\ Corresponding author: Said G. Osman, gotoaila@gmail.com
}

\begin{abstract}
\section{Introduction}

Several minimally invasive spine approaches and techniques have been developed in recent years. While the disease processes affecting the spinal motion segment have remained largely the same, the emerging technologies have changed treatment options radically and not necessarily in an organized fashion. The current diagnostic techniques, also evolving, have helped us appreciate the disease's pathoanatomy in minute details. A comprehensive classification method accounting for all anatomical variations in the disc disease, tailored to treatment options, is necessary. Such a classification will allow the surgeon to choose an appropriate surgical option in a consistent fashion. We feel that our classification system will help the spine surgeon make that important decision consistently, with minimal risk of leaving behind a significant lesion or disrupting an otherwise normal structure of the spinal motion segment. Furthermore, we feel such a comprehensive classification will help surgeons and other caregivers to standardize treatment approaches to the various presentations of disc disease, and apply the evolving technology in an organized fashion.
\end{abstract}

\section{Purpose}

To develop a comprehensive, treatment-orientated classification of the lumbar disc disease.

\section{Materials and Methods}

The literature was reviewed for the classification of disc disease. The morphology of the disc disease, the topography of the disc lesion, and the symptom-complex produced by the disc lesion are identified and graded. The features so identified and graded are placed in a matrix. The combinations of the anatomical features and symptoms are then computed as shown in the matrix. The MRI database held in the office was studied to determine the most frequent combinations of the disc disease and symptom complex.

\section{Results}

A total of 494 combinations were identified, but most have no clinical relevance. The retrospective study of the clinical data and MRI studies of 93 patients ( 50 male and 43 female) revealed the most affected motionsegment was L5-S1 (male $=19.3 \%$, and female $=23.8 \%$ ). The most common patho-anatomy is a globally bulging disc (T3L1), representing $37.6 \%$ of the total. The second most common combination is a degenerated disc with central, intra-annular tear T4L1), representing $20.4 \%$ of the total. At $11.8 \%$, globally bulging with severe axial pain and moderate radicular pain represented the most common patho-anatomic/clinical classification (T3L1B4R2). The most frequent top 10 patho-anatomic/clinical classifications represented $15.5 \%$ of the total.

C) Copyright 2021

Osman. This is an open access article distributed under the terms of the Creative Commons Attribution License CC-BY 4.0., which permits unrestricted use, distribution, and reproduction in any medium, provided the original author and source are credited.

\section{Conclusion}

In light of the multiple surgical options for excision of the herniated lumbar disc, including the conventional and minimally invasive, and the fact that the imaging technology allows spine surgeons to see in great detail, the disease status of each of the components of the spinal motion segment, it is imperative to develop comprehensive classification systems which take account of the unique characteristics of the disease entity and guide treatment strategies. The classification system presented here is fairly complex, but the software technology will be utilized for the classification system along with the most appropriate treatment approach.

Categories: Radiology, Orthopedics, Anatomy

Keywords: anatomic, image-based, lumbar, disc, topography, morphology, spinal endoscopy, trans-iliac, transforaminal, interlaminar

\section{Introduction}

This article was previously presented as an abstract in the May/June 2015 Pain Physician Journal. 
Recently, Osman, et al. presented a novel comprehensive anatomic, image-based classification of lumbar spinal motion segment degeneration [1]. That classification grades the patho-anatomy of the intervertebral disc, facet joint, ligamentum flavum, and alignment of the spinal motion segment, presenting the combinations of the four structural abnormalities as a code. Along with the patient's complete clinical data, the classification is then used to determine appropriate surgical options in a hierarchical manner - with the least invasive and most effective option being the first offered. Based on that classification system, the disc may be the only abnormal structure, and the symptoms may be entirely or mostly related to the disc abnormality. This treatment-based classification of the lumbar intervertebral disc pathology is used in conjunction with the motion-segment classification for comprehensive management of the motion-segment disease. Hitherto, diseases of the lumbar intervertebral disc have been classified according to various attributes of the condition. Spengler et al. [2] classified disc pathology according to its morphology protrusion (contained within the annulus), extrusion (annulus torn but herniation in continuity with disc interior), and sequestrated.

Disc rupture may be classified according to its topographic location - central, lateral recess, foraminal and extra-foraminal. Disc herniations have also been classified according to the timing of the surgical intervention as this has prognostic significance [3-5]. Disc herniation may occur early in the degenerative cascade or late in the degeneration of the disc. The classifications currently available convey valuable information about the nature of herniation; however, they are all stand-alone classifications that fail to take into account the other players in the spinal motion segment. Until recently, the approach to a herniated lumbar disc or spinal stenosis has been posteriorly, through open laminotomy or laminectomy, hence, there was no need for complex classification of the herniated disc for the purpose of determining the surgical approach. However, over the last couple of decades, a number of minimally invasive treatment options for lumbar disc herniations have emerged [6-9]. These include, but are not limited to, the percutaneous endoscopic transforaminal approach, the percutaneous endoscopic interlaminar approach, and the miniopen interlaminar approach. Osman et al., in a cadaver study, described a detailed

endoscopic transforaminal approach to all levels from the upper thoracic spine to the sacrum [10]. In another cadaver study, the authors also demonstrated the superiority of the transforaminal endoscopic approach as compared to laminectomy and partial facetectomy, both in terms of better foraminal decompression, maintenance of motion-segment stability, and minimalization of collateral structural damage [11]. Unlike the traditional laminectomy and laminotomy where the pre-incision concerns are mainly the identification of the level and side of the lesion, with the new minimally invasive techniques many additional considerations are critical. These include the topographical location of disc lesion, its morphology, migration of free fragment herniation, and the direction of the migration. Unfortunately, as these very useful, tissue-preserving techniques emerge, there is no universal system of classification to determine which approach is most suitable for a given disc pathological configuration. This state of affairs creates confusion in the minds of those who want to learn these techniques and make progress in the harnessing of the new technologies for the benefit of their patients. While all the new developments are exciting, it is important to appreciate that the new technologies may not be able to solve some of the problems we encounter in disc surgery. It is the aim of this classification to detail the anatomical as well as the sign and symptoms of the patient to give recommendations for the most appropriate surgical approaches in a hierarchical manner.

\section{Materials And Methods}

The morphologic and topographic aspects of the intervertebral disc and the clinical manifestations of the disc pathology are graded as listed in Table 1.

\begin{tabular}{|c|c|c|c|}
\hline Type of disc ruptures & Location of disc rupture & Radicular symptom/sign & $\begin{array}{l}\text { Back pain (VAS } \\
\text { score) }\end{array}$ \\
\hline T1 = Acute Intra-annular & L1 = Central herniation & R0 $=$ None & $\mathrm{B} 0=0$ \\
\hline T2 = Acute Extra-annular & L2 = Paracentral - Pre-dural & R1 = Mild paresthesia. & $B 1=1-2 / 10$ \\
\hline $\begin{array}{l}\text { T3 = Degenerated, globally } \\
\text { bulging }\end{array}$ & L3 = Paracentral - Axillary & $\begin{array}{l}\mathrm{R} 2 \text { = Moderate pain, } 4 / 5 \text { muscle } \\
\text { power. }\end{array}$ & $B 2=3-6 / 10$ \\
\hline T4 = Degenerate Intra-annular & $\begin{array}{l}\text { L4 = Paracentral - Pre- } \\
\text { Radicular }\end{array}$ & R3 = Severe pain, $3 / 5$ muscle power & B3 = 7-9/10 \\
\hline T5 = Degenerate, Extra-annular & L5 = Intra- extra foraminal & R4 = Numb, $=0-2 / 5$ muscle power & $B 4=10 / 10$ \\
\hline
\end{tabular}

TABLE 1: Anatomic Classification of Disc Pathology and Grading of Clinical Findings 


\section{Cureus}

are placed in a matrix and the combinations are recorded as shown in Table 2.

\begin{tabular}{|c|c|c|c|c|c|c|}
\hline & $\begin{array}{l}\text { Acute Intra- } \\
\text { annular- }\left(T_{1}\right)\end{array}$ & $\begin{array}{l}\text { Acute-Extra- } \\
\text { annular - }\left(\mathrm{T}_{2}\right)\end{array}$ & $\begin{array}{l}\text { Global } \\
\text { bulge }\left(T_{3}\right)\end{array}$ & $\begin{array}{l}\text { Deg Intra- } \\
\text { annular }\left(T_{4}\right)\end{array}$ & $\begin{array}{l}\text { Deg-Extra- } \\
\text { annular }\left(T_{5}\right)\end{array}$ & \\
\hline $\begin{array}{l}\text { Central herniation } \\
\left(L_{1}\right)\end{array}$ & $L_{1} T_{1} B_{0} R_{0}$ & $\mathrm{~L}_{1} \mathrm{~T}_{2} \mathrm{~B}_{0} \mathrm{R}_{\mathrm{I}}$ & $\mathrm{L}_{1} \mathrm{~T}_{3} \mathrm{~B}_{0} \mathrm{R}_{2}$ & $\mathrm{~L}_{1} \mathrm{~T}_{4} \mathrm{~B}_{0} \mathrm{R}_{3}$ & $\mathrm{~L}_{1} \mathrm{~T}_{5} \mathrm{~B}_{0} \mathrm{R}_{4}$ & $\begin{array}{l}\text { Back pain - } \\
\left(B_{0}\right)\end{array}$ \\
\hline PC-Pre-dural ( $\left.\mathrm{L}_{2}\right)$ & $\mathrm{L}_{2} \mathrm{~T}_{1} \mathrm{~B}_{1} \mathrm{R}_{0}$ & $\mathrm{~L}_{2} \mathrm{~T}_{2} \mathrm{~B}_{1} \mathrm{R}_{1}$ & $\mathrm{~L}_{2} \mathrm{~T}_{3} \mathrm{~B}_{2} \mathrm{R}_{2}$ & $\mathrm{~L}_{2} \mathrm{~T}_{4} \mathrm{~B}_{1} \mathrm{R}_{3}$ & $\mathrm{~L}_{2} \mathrm{~T}_{5} \mathrm{~B}_{1} \mathrm{R}_{4}$ & $\begin{array}{l}\text { Back pain - } \\
\left(B_{1}\right)\end{array}$ \\
\hline PC-Axillary (L3) & $\mathrm{L}_{3} \mathrm{~T}_{1} \mathrm{~B}_{2} \mathrm{R}_{0}$ & $\mathrm{~L}_{3} \mathrm{~T}_{2} \mathrm{~B}_{2} \mathrm{R}_{1}$ & $\mathrm{~L}_{3} \mathrm{~T}_{3} \mathrm{~B}_{2} \mathrm{R}_{2}$ & $\mathrm{~L}_{3} \mathrm{~T}_{4} \mathrm{~B}_{2} \mathrm{R}_{3}$ & $\mathrm{~L}_{3} \mathrm{~T}_{5} \mathrm{~B}_{2} \mathrm{R}_{4}$ & $\begin{array}{l}\text { Back pain - } \\
\left(B_{2}\right)\end{array}$ \\
\hline $\begin{array}{l}\text { PC-Pre-Radicular - } \\
\left(\mathrm{L}_{4}\right)\end{array}$ & $L_{4} T_{1} B_{3} R_{0}$ & $\mathrm{~L}_{4} \mathrm{~T}_{2} \mathrm{~B}_{3} \mathrm{R}_{1}$ & $L_{4} T_{3} B_{3} R_{2}$ & $\mathrm{~L}_{4} \mathrm{~T}_{4} \mathrm{~B}_{3} \mathrm{R}_{3}$ & $\mathrm{~L}_{4} \mathrm{~T}_{5} \mathrm{~B}_{3} \mathrm{R}_{4}$ & $\begin{array}{l}\text { Back pain - } \\
\left(\mathrm{B}_{3}\right)\end{array}$ \\
\hline \multirow[t]{2}{*}{$\begin{array}{l}\text { Intra- extra } \\
\text { foraminal }\left(L_{5}\right)\end{array}$} & $\mathrm{L}_{5} \mathrm{~T}_{1} \mathrm{~B}_{4} \mathrm{R}_{0}$ & $\mathrm{~L}_{5} \mathrm{~T}_{2} \mathrm{~B}_{4} \mathrm{R}_{1}$ & $L_{5} T_{3} B_{4} R_{2}$ & $\mathrm{~L}_{5} \mathrm{~T}_{4} \mathrm{~B}_{4} \mathrm{R}_{3}$ & $\mathrm{~L}_{5} \mathrm{~T}_{5} \mathrm{~B}_{4} \mathrm{R}_{4}$ & $\begin{array}{l}\text { Back pain - } \\
\left(B_{4}\right)\end{array}$ \\
\hline & Radcular - $\left(\mathbf{R}_{0}\right)$ & Radicular - $\left(\mathbf{R}_{\mathbf{1}}\right)$ & $\begin{array}{l}\text { Radicular- } \\
\text { (R2) }\end{array}$ & Radicular - $\left(\mathbf{R}_{3}\right)$ & $\begin{array}{l}\text { Radicular - CES } \\
\left(\mathbf{R}_{\mathbf{4}}\right)\end{array}$ & \\
\hline
\end{tabular}

TABLE 2: Matrix of Pathoanatomy and Clinical Gradings

Based on the patho-anatomic identifications, the MRI images and drawings of the lumbar discs are presented in Figures 1 to 10.

Figure 1 shows intra-annular tear, with the nuclear protrusion being contained within the outer layers of the annular wall.
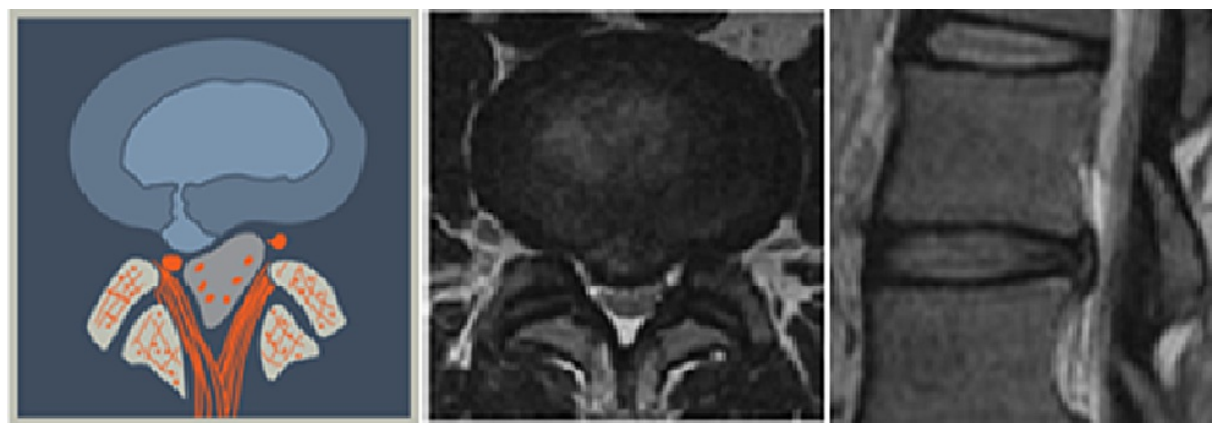

FIGURE 1: Acute Intra-Annular Tear (T1)

This is the rupture of a normal disc where the protruding nuclear material is contained within the annular wall. 


\section{Cureus}

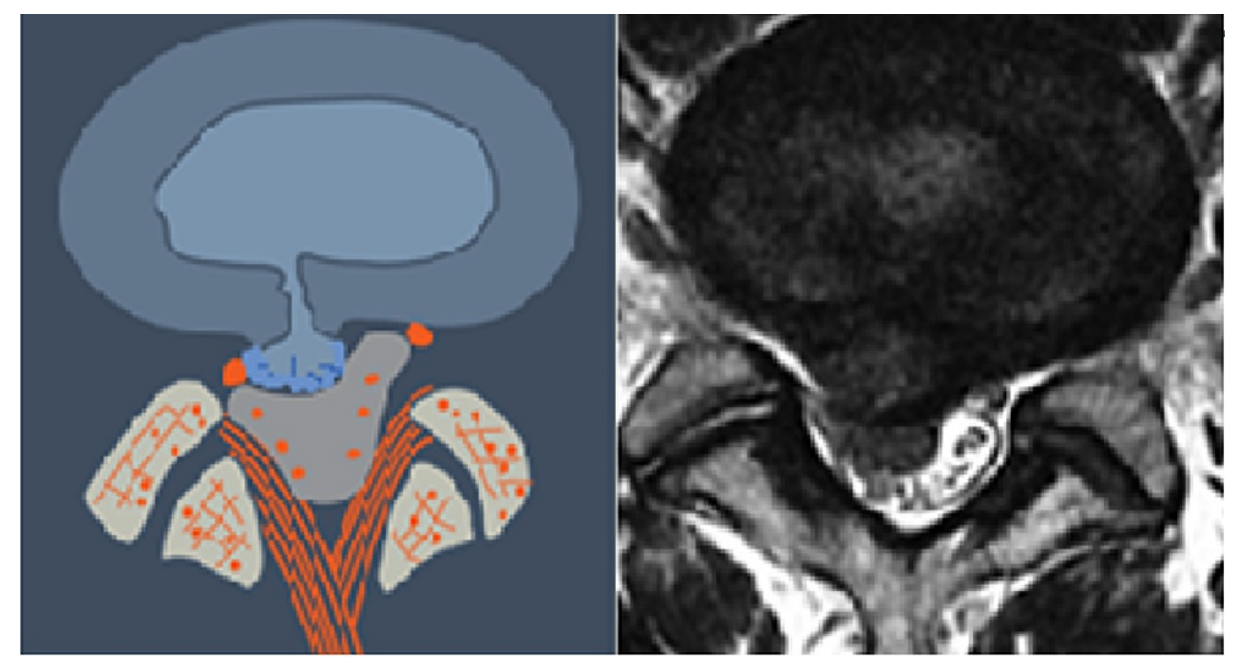

FIGURE 2: Acute Extra-Annular Tear (T2)

This is rupture of a normal disc where the nuclear material extrudes through the annulus and may be a free fragment.

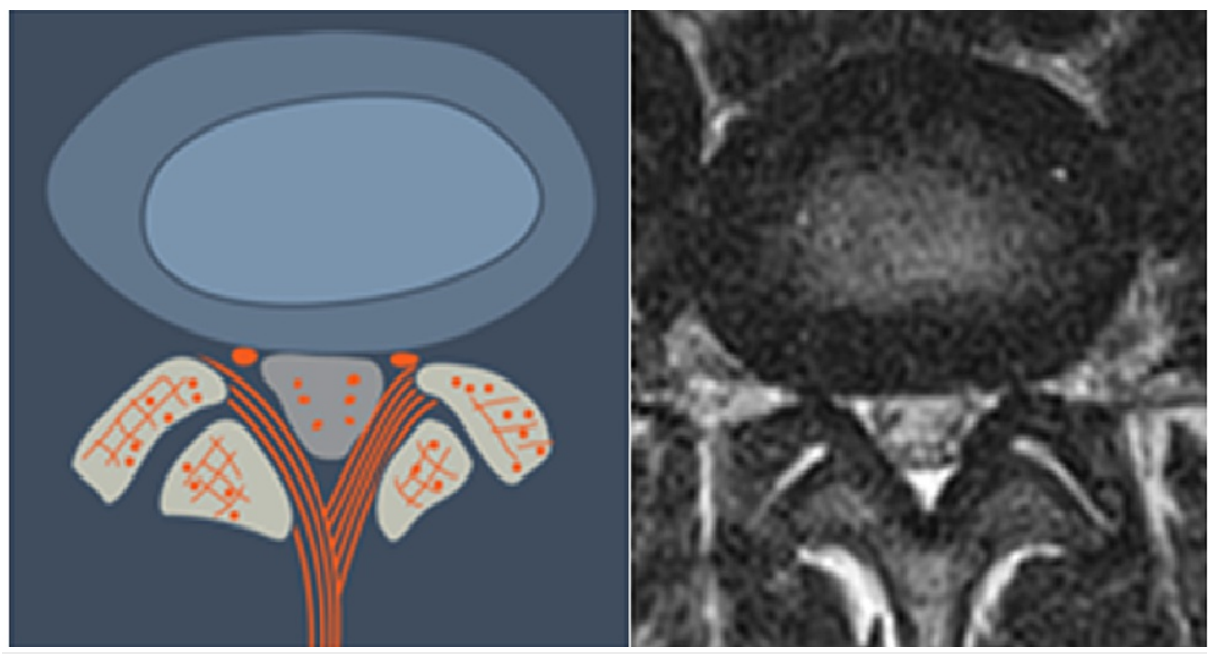

FIGURE 3: Global Disc Bulge (T3)

This is a degenerated disc which bulges globally. The disc height is usually reduced. The nuclear materal is contained within the bulging annulus. 


\section{Cureus}
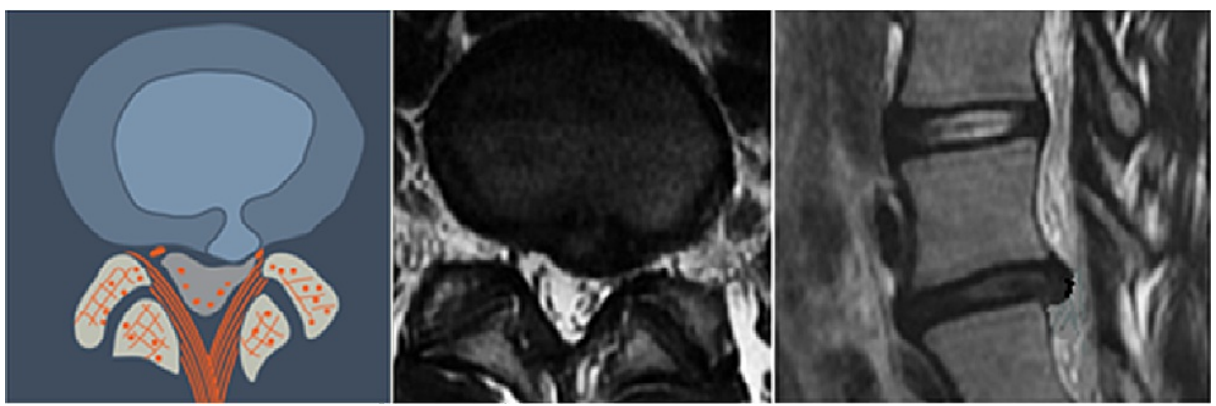

\section{FIGURE 4: Intra-Annular Herniation (T4)}

This is a degenerated disc with weakend annular where the herniated nuclear fragment is contained within the annular wall.
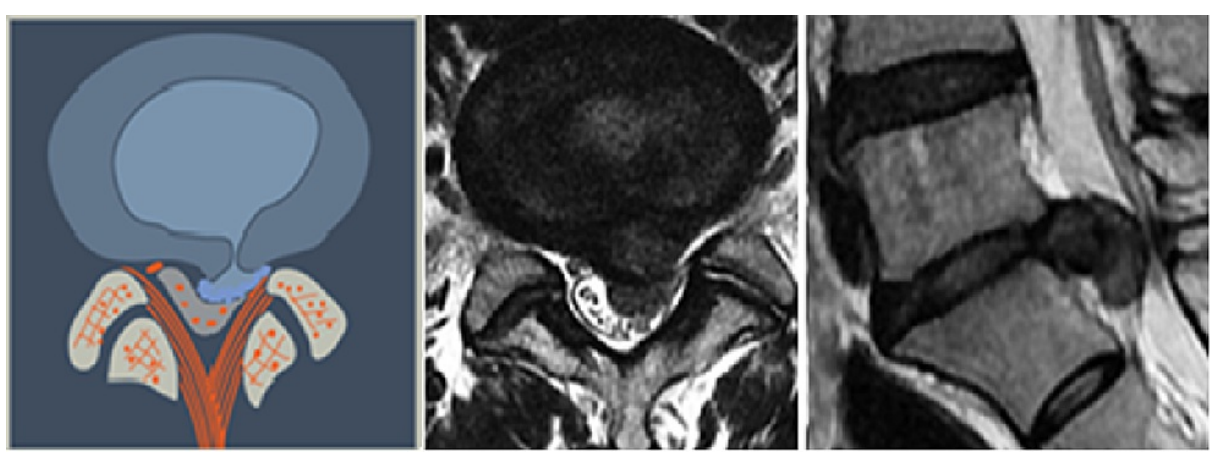

FIGURE 5: Extra-Annular Herniation, Degenerated Disc (T5)

This is a degenerated disc which weakened annular wall. The nuclear material has extruded through the annulus and may migrate caudally or cranially.
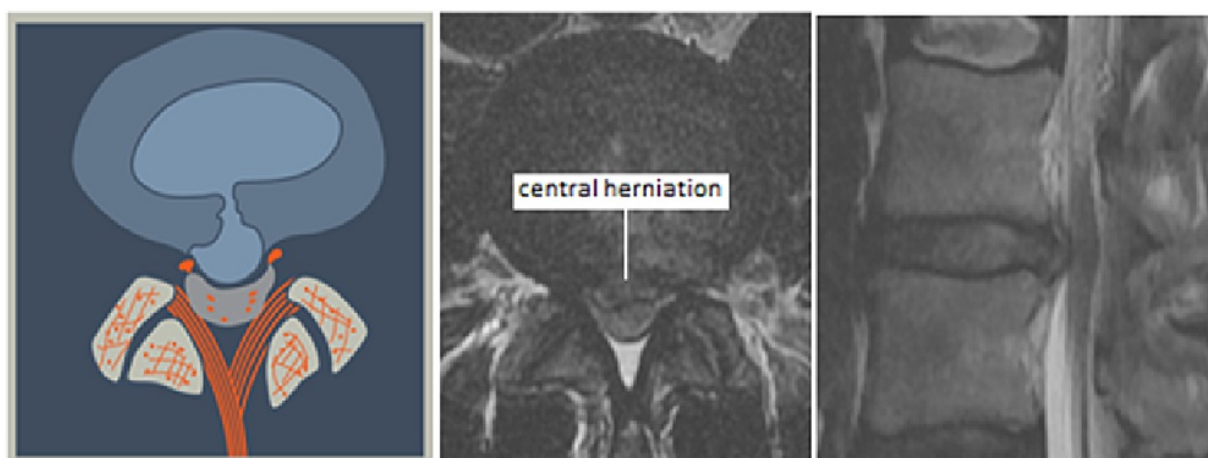

FIGURE 6: Central Herniation (L1)

This may be a normal or degenerated disc which ruptures into the center of the spinal canal, directly ventral to the posterior longitudinal ligament. The herniated nuclear material may be contained with the annular wall (intra-annular) or extruded though the annulus (extra-annular). 


\section{Cureus}

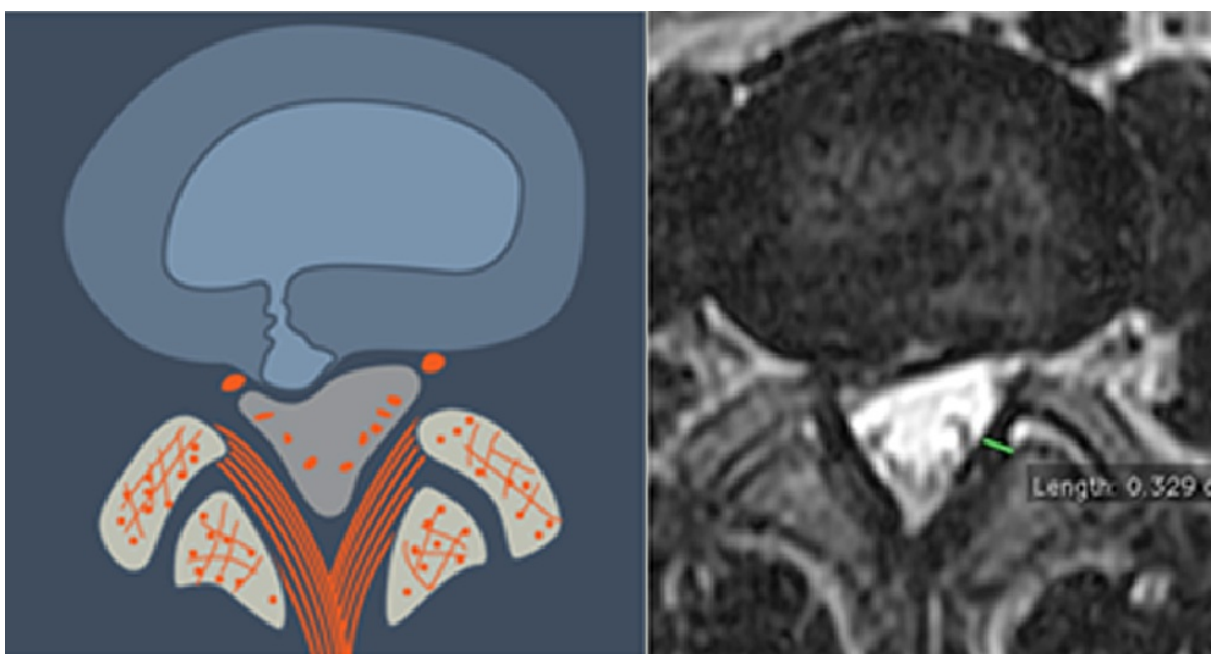

FIGURE 7: Paracentral, Predural Herniation (L2)

The herniation is paracentral and may be on the right or the left side of the midline. Topographically it is found ventral to the dura and may extend to the midline.

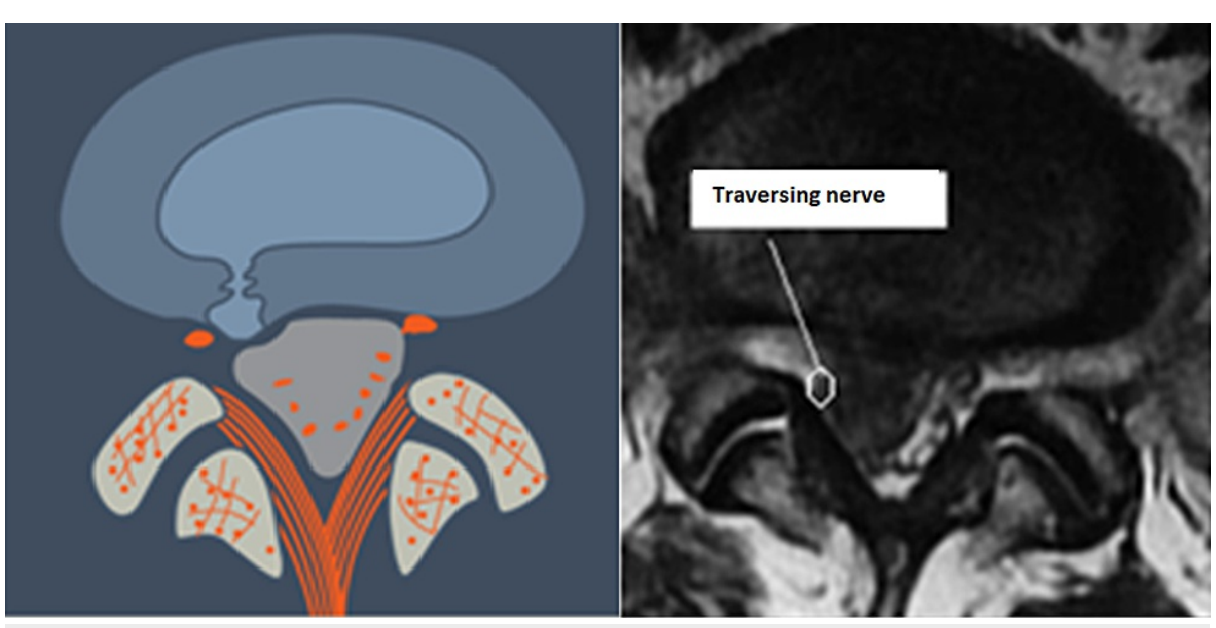

FIGURE 8: Paracentral, Axillary (L3)

The herniation is paracentral and is lodged between the dura, medially, and the traversing nerve root laterally. The herniated material may be intra-annular or extra-annular (i.e. extruded). 


\section{Cureus}
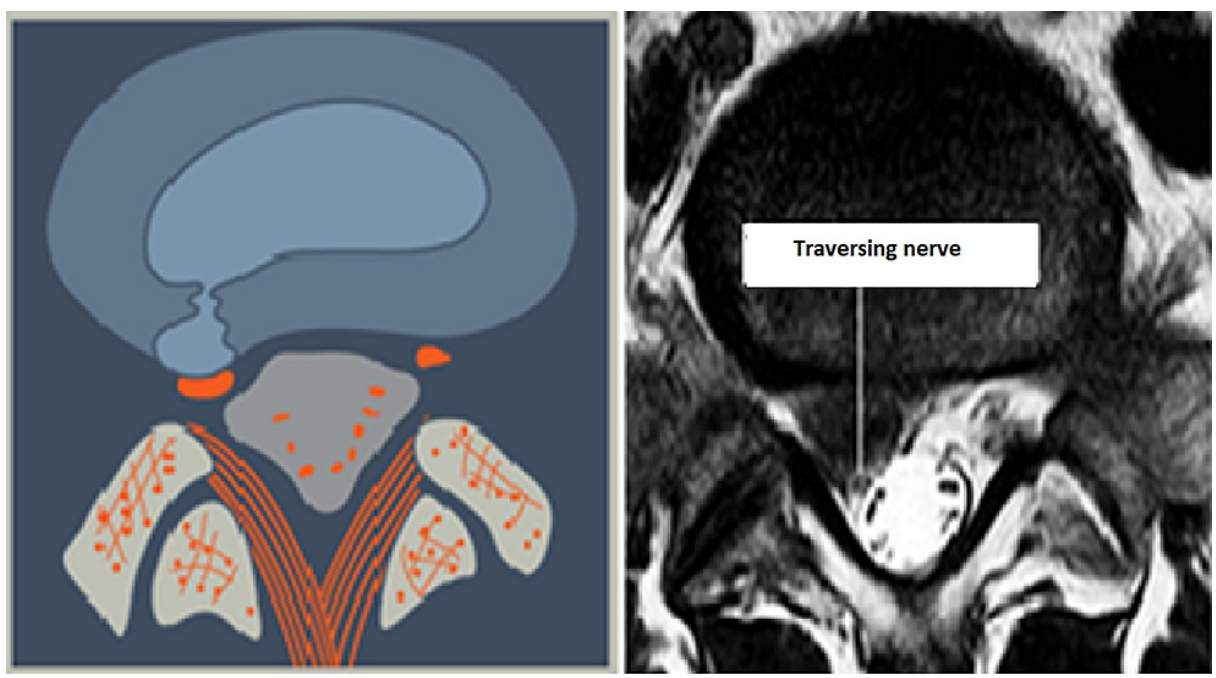

\section{FIGURE 9: Paracentral, Pre-Radicular Herniation (L4)}

The herniation is paracentral and situated ventral to the traversing nerve. The nerve is usually draped around the herniated material making it vulnerable to injury when approached posteriorly.

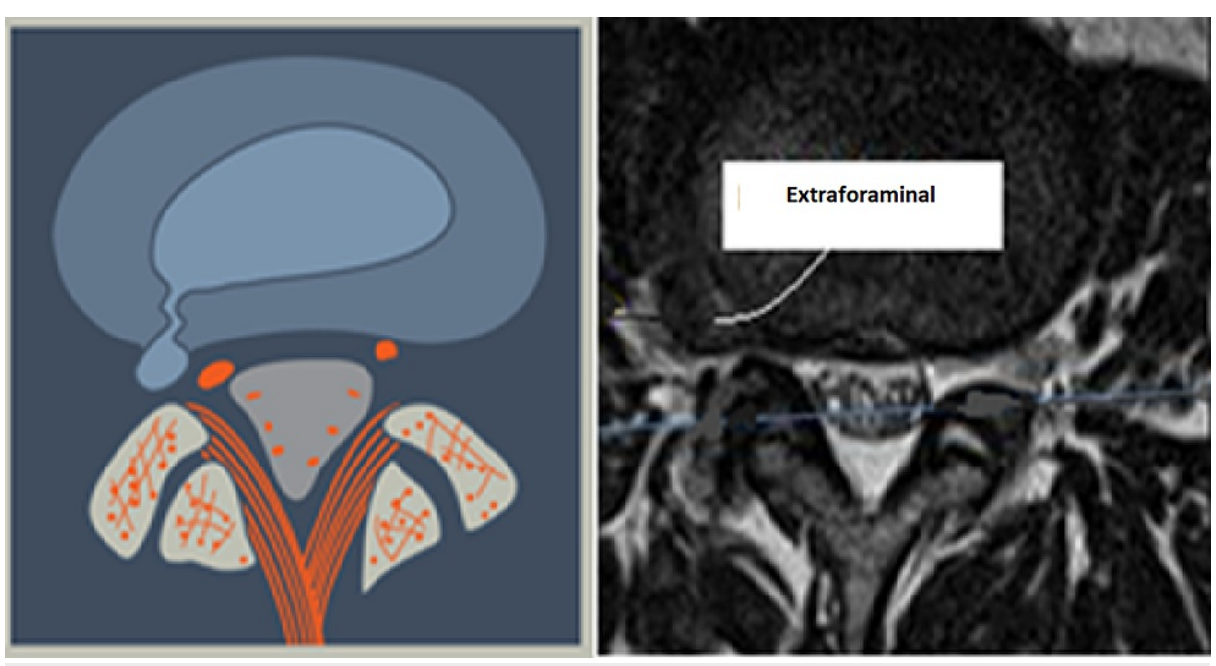

FIGURE 10: Intra-/Extra-Foraminal Herniation (L5)

The herniation may be in the foraminal or extraforaminal location. This may be a normal disc or degenerated disc which ruptured, and the nuclear material may be intra- or extra-annular. The hernia usually is very close to the exiting nerve root. especially if it is extraforaminal.

\section{Results}

A total of 494 combinations were identified using the matrix in Table 2. Most of the combinations have no clinical relevance, hence, a retrospective study of the office database was carried out to determine the prevalence of the various patho-anatomic combinations. The medical records and lumbar MRI films of 93 patients were studied (50 male and 43 female). The age range was $28-79$ years. The most affected motion segment was L5-S1, both in male and female populations - 19.3\% and 23.8\%, respectively (Table 3). 


\section{Cureus}

\begin{tabular}{|c|c|c|c|c|c|c|}
\hline \multirow{3}{*}{ Level } & \multicolumn{4}{|c|}{ Sex } & \multirow{2}{*}{\multicolumn{2}{|c|}{ Total }} \\
\hline & \multicolumn{2}{|l|}{ M } & \multicolumn{2}{|l|}{$\mathrm{F}$} & & \\
\hline & $\#$ & $\%$ & \# & $\%$ & \# & $\%$ \\
\hline L5-S1 & 17 & 19.3 & 21 & 23.9 & 38 & 43.2 \\
\hline L4-5 & 16 & 18.2 & 16 & 18.2 & 32 & 36.4 \\
\hline L3-4 & 6 & 6.8 & 4 & 4.5 & 10 & 11.4 \\
\hline L2-3 & 4 & 4.5 & 1 & 1.1 & 5 & 5.7 \\
\hline L1-2 & 1 & 1.1 & 2 & 2.3 & 3 & 3.4 \\
\hline Total & 44 & 50 & 44 & 50 & 88 & 100 \\
\hline
\end{tabular}

TABLE 3: Prevalence of Disc Lumbar Disc Disease Based on the Motion-Segment Levels.

The most common disc patho-anatomic combination (i.e., morphology and topography) degenerates and globally bulging disc (T3L1), representing $37.6 \%$ of the total (Table 4). The next most common combination of the patho-anatomy is the central intra-annular herniation of a degenerated disc, representing $20.4 \%$ (T4L1).

\begin{tabular}{|c|c|c|c|c|c|c|}
\hline \multirow{3}{*}{ Level } & \multicolumn{4}{|c|}{ Sex } & \multirow{2}{*}{\multicolumn{2}{|c|}{ Total }} \\
\hline & \multicolumn{2}{|l|}{ M } & \multicolumn{2}{|l|}{$F$} & & \\
\hline & \# & $\%$ & \# & $\%$ & \# & $\%$ \\
\hline T3L1 & 18 & 19.4 & 17 & 18.3 & 35 & 37.6 \\
\hline T4L1 & 10 & 10.8 & 9 & 9.7 & 19 & 20.4 \\
\hline T4L4 & 7 & 7.5 & 5 & 5.4 & 12 & 12.9 \\
\hline T5L4 & 5 & 5.4 & 3 & 3.2 & 8 & 8.6 \\
\hline T4L5 & 3 & 3.2 & 3 & 3.2 & 6 & 6.5 \\
\hline T4L2 & 4 & 4.3 & 1 & 1.1 & 5 & 5.4 \\
\hline T5L2 & 0 & 0.0 & 4 & 4.3 & 4 & 4.3 \\
\hline T5L3 & 1 & 1.1 & 1 & 1.1 & 2 & 2.2 \\
\hline T5L1 & 1 & 1.1 & 0 & 0.0 & 1 & 1.1 \\
\hline T3L4 & 1 & 1.1 & 0 & 0.0 & 1 & 1.1 \\
\hline Total & 50 & 53.8 & 43 & 46.2 & 93 & 100 \\
\hline
\end{tabular}

TABLE 4: Common combinations of the patho-anatomic lumbar disc morphology and topography.

Table 5 shows the most common gradings of the lumbar disc patho-anatomy and clinical findings. At $11.8 \%$, globally bulging, degenerated disc presenting with severe lumbar pain and moderate radicular pain (T3L1B4R2) is the most common classification. The ten most frequent classifications, representing $15.5 \%$ of the total patho-anatomic and clinical grading, included degenerated and globally bulging discs with or without intranuclear, central herniation. 


\begin{tabular}{|c|c|c|c|c|c|c|}
\hline \multirow{3}{*}{ Path/Clin Comb } & \multicolumn{4}{|c|}{ Sex } & \multirow{2}{*}{\multicolumn{2}{|c|}{ Total }} \\
\hline & \multicolumn{2}{|c|}{ M } & \multicolumn{2}{|l|}{$\mathrm{F}$} & & \\
\hline & \# & $\%$ & \# & $\%$ & \# & $\%$ \\
\hline T3L1B4R2 & 7 & 7.5 & 4 & 4.3 & 11 & 11.8 \\
\hline T3L1B3R2 & 5 & 5.4 & 2 & 2.2 & 7 & 7.5 \\
\hline T4L1B3R2 & 2 & 2.2 & 5 & 5.4 & 7 & 7.5 \\
\hline T4L4B3R2 & 3 & 3.2 & 4 & 4.3 & 7 & 7.5 \\
\hline T5L4B2R3 & 3 & 3.2 & 2 & 2.2 & 5 & 5.4 \\
\hline T4L1B4R2 & 2 & 2.2 & 2 & 2.2 & 4 & 4.3 \\
\hline T3L1B4R3 & 2 & 2.2 & 1 & 1.1 & 3 & 3.2 \\
\hline T4L5B2R2 & 1 & 1.1 & 2 & 2.2 & 3 & 3.2 \\
\hline T3L1B2R1 & 0 & 0.0 & 2 & 2.2 & 2 & 2.2 \\
\hline T3L1B2R3 & 1 & 1.1 & 1 & 1.1 & 2 & 2.2 \\
\hline
\end{tabular}

TABLE 5: Prevalence of patho-anatomic and clinical features classification.

\section{Discussion}

After comprehensive non-operative treatment, including activity modifications, pain medication, rehabilitation measures, and therapeutic injections have been utilized, persistent symptoms may require surgical intervention. The spectrum of procedures practiced today for lumbar discectomy includes percutaneous discectomy [12-14], endoscopic transforaminal discectomy [15], interlaminar endoscopic approaches [16,17], laminotomy, laminectomy [18-20], and variable degrees of facetectomy. Posterior procedures including laminotomy and laminectomy involve some degree of paraspinal muscle mobilization, excision of bony structures, and traversing the spinal canal to gain access to the pathologic disc, ventral to the dura. The consequences of such interventions may include damage to the paraspinal musculature, compromise spinal stability, and creation of epidural scar which may render subsequent surgical intervention difficult. This anatomic treatment-based disc disease classification system presents imagebased morphologic and topographic grading combined with the patient's symptom-complex, and helps guide surgical approach for predominantly radicular deficits while incurring the least amount of disruption of normal structures. Based on the morphology, topography, and migration of a free fragment herniation, and other considerations, the surgeon may choose a transforaminal, interlaminar, open, or endoscopic approach. The comprehensive spinal-motion segment classification, recently described by the author [1] should be utilized to determine the appropriate surgical option if other structures of the spinal-motion segment are implicated in the symptom complex.

With such a comprehensive anatomic treatment-based classification it is hoped that the diverse technological advancement $[6,7,11,13]$ in the surgical treatment of the lumbar spine will be applied in a rational manner, and that spine professionals can compare the relative effectiveness of the various surgical options for the different structural characteristics of the disc lesion in precise anatomic fashion as opposed to the vague characterization of the patho-anatomy practiced currently.

Often, surgeons see patients who present with radicular pain but minimal or no back pain. A review of the imaging studies, however, may reveal degeneration of the facet joints associated with foraminal stenosis and some mal-alignment of the motion segment. These patients are likely to be middle-aged or elderly. In spite of the findings on the images, limiting surgical intervention to relieve the radicular pain is often sufficient. Hence, it is critical that the pain generator is precisely defined utilizing an image-based, anatomic classification of spinal motion segments [1]. The classification grades the degree of abnormality of each component of the spinal motion segment. With pre-operative diagnostic/therapeutic injections the pain generator can be accurately determined and targeted with the least invasive surgical technique if needed.

\section{Conclusions}

As the understanding of the patho-anatomy and pain generators improve, as the risks and benefits of different surgical approaches become appreciated, and as the cost-benefit analysis of each approach become appreciated, with the evolution of the least invasive spine technologies, this anatomic classification along 
with anatomic motion-segment classification will make it possible to make appropriate choices of surgical approaches. Furthermore, such anatomic classification systems will make the comparisons of different surgical approaches more accurate and, thus, help the surgeon make appropriate surgical approach decision.

\section{Additional Information \\ Disclosures}

Human subjects: All authors have confirmed that this study did not involve human participants or tissue. Animal subjects: All authors have confirmed that this study did not involve animal subjects or tissue. Conflicts of interest: In compliance with the ICMJE uniform disclosure form, all authors declare the following: Payment/services info: All authors have declared that no financial support was received from any organization for the submitted work. Financial relationships: All authors have declared that they have no financial relationships at present or within the previous three years with any organizations that might have an interest in the submitted work. Other relationships: All authors have declared that there are no other relationships or activities that could appear to have influenced the submitted work.

\section{References}

1. Osman SG, Narayanan M, Winters C: Anatomic treatment-based classificaton of diseased lumbar spinal motion-segment. IJNSS. 2013, 1:1-10.

2. Spengler DM, Oullette EA, Battié M, Zeh J: Elective discectomy for a herniated lumbar disc: additional experience with an objective method. . J Bone Joint Surg Am. 1990, 72. : 320-327.

3. Hurme M, Alaranta H: Factors predicting the result of surgery for lumbar intervertebral disc herniation . Spine (Phila Pa 1976). 1987, 12:933-8. 10.1097/00007632-198711000-00016

4. Nygaard OP, Kloster R, Solberg T: Duration of leg pain as a predictor of outcome after surgery for lumbar disc herniation: a prospective cohort study with 1-year follow up. J Neurosurg. 2000, 92:131-4. 10.3171/spi.2000.92.2.0131

5. Rothoerl RD, Woertgen C, Brawanski A: When should conservative treatment for lumbar disc herniation be ceased and surgery considered?. Neurosurg Rev. 2002, 25:162-5. 10.1007/s101430100184

6. Kambin P: Arthroscopic microdiscectomy. Arthroscopy. 1992, 8:287-95. 10.1016/0749-8063(92)90058-j

7. Yeung AT, Tsou PM: Posterolateral endoscopic excision for lumbar disc herniation: surgical technique, outcome, and complications in 307 consecutive cases. Spine (Phila Pa 1976). 2002, 27:722-31. 10.1097/00007632-200204010-00009

8. Osman SG, Marsolais EB: Endoscopic transiliac approach to L5-S1 disc and foramen. A cadaver study . Spine (Phila Pa 1976). 1997, 22:1259-63. 10.1097/00007632-199706010-00020

9. Kogias E, Vougioukas VI, Hubbe U, Halatsch ME: Minimally invasive approach for the treatment of lateral lumbar disc herniations. Technique and results. Minim Invasive Neurosurg. 2007, 50:160-2. 10.1055/s-2007985143

10. Osman SG, Marsolais EB: Posterolateral arthroscopic discectomies of the thoracic and lumbar spine . Clin Orthop Relat Res. 1994, 122-9.

11. Osman SG, Nibu K, Panjabi MM, Marsolais EB, Chaudhary R: Transforaminal and posterior decompressions of the lumbar spine. A comparative study of stability and intervertebral foramen area. Spine (Phila Pa 1976). 1997, 22:1690-5. 10.1097/00007632-199708010-00002

12. Filippiadis DK, Kelekis A: A review of percutaneous techniques for low back pain and neuralgia: current trends in epidural infiltrations, intervertebral disk and facet joint therapies. Br J Radiol. 2015, 89:20150357. 10.1259/bjr.20150357

13. Buy X, Gangi A: Percutaneous treatment of intervertebral disc herniation . Semin Intervent Radiol. 2010, 27:148-59. 10.1055/s-0030-1253513

14. Zhu H, Zhou XZ, Cheng MH, Shen YX, Dong QR: The efficacy of coblation nucleoplasty for protrusion of lumbar intervertebral disc at a two-year follow-up. Int Orthop. 2011, 35:1677-82. 10.1007/s00264-010-11960

15. Choi KC, Kim JS, Kang BU, Lee CD, Lee SH: Changes in back pain after percutaneous endoscopic lumbar discectomy and annuloplasty for lumbar disc herniation: a prospective study. Pain Med. 2011, 12:1615-21. 10.1111/j.1526-4637.2011.01250.x

16. Komp M, Hahn P, Merk H, Godolias G, Ruetten S: Bilateral operation of lumbar degenerative central spinal stenosis in full-endoscopic interlaminar technique with unilateral approach: prospective 2-year results of 74 patients. J Spinal Disord Tech. 2011, 24:281-7. 10.1097/BSD.0b013e3181f9f55e

17. Young S, Veerapen R, O'Laoire SA: Relief of lumbar canal stenosis using multilevel subarticular fenestrations as an alternative to wide laminectomy: preliminary report. Neurosurgery. 1988, 23:628-33. 10.1227/00006123-198811000-00014

18. Verbiest H: Results of surgical treatment of idiopathic developmental stenosis of the lumbar vertebral canal. A review of twenty-seven years' experience. J Bone Joint Surg Br. 1977, 59:181-8. 10.1302/0301620X.59B2.141452

19. Getty CJ: Lumbar spinal stenosis: the clinical spectrum and the results of operation . J Bone Joint Surg Br. 1980, 62-B:481-5. 10.1302/0301-620X.62B4.6448861

20. Airaksinen O, Herno A, Saari T: Surgical treatment of lumbar spinal stenosis: patients' postoperative disability and working capacity. Eur Spine J. 1994, 3:261-4. 10.1007/BF02226576 